\title{
Timber volume estimation based on airborne laser scanning - comparing the use of national forest inventory and forest management inventory data
}

\author{
Johannes Rahlf ${ }^{1} \cdot$ Marius Hauglin $^{1} \cdot$ Rasmus Astrup ${ }^{1}$. Johannes Breidenbach ${ }^{1}$
}

Received: 26 October 2020 / Accepted: 25 March 2021 / Published online: 17 May 2021

(C) The Author(s) 2021

\begin{abstract}
- Key message Large-scale forest resource maps based on national forest inventory (NFI) data and airborne laser scanning may facilitate synergies between NFIs and forest management inventories (FMIs). A comparison of models used in such a NFI-based map and a FMI indicate that NFI-based maps can directly be used in FMIs to estimate timber volume of mature spruce forests.
\end{abstract}

- Context Traditionally, FMIs and NFIs have been separate activities. The increasing availability of detailed NFI-based forest resource maps provides the possibility to eliminate or reduce the need of field sample plot measurements in FMIs if their accuracy is similar.

- Aims We aim to (1) compare a timber volume model used in a NFI-based map and models used in a FMI, and (2) evaluate utilizing additional local sample plots in the model of the NFI-based map.

- Methods Accuracies of timber volume estimates using models from an existing NFI-based map and a FMI were compared at plot and stand level.

- Results Estimates from the NFI-based map were similar to or more accurate than the FMI. The addition of local plots to the modeling data did not clearly improve the model of the NFI-based map.

- Conclusion The comparison indicates that NFI-based maps can directly be used in FMIs for timber volume estimation in mature spruce stands, leading to potentially large cost savings.

Keywords Remote sensing $\cdot$ Lidar $\cdot$ Mixed model $\cdot$ Forest resource map $\cdot$ Large-scale mapping

\section{Introduction}

Forest management inventories (FMIs) in the Nordic countries (Næsset et al. 2004) mainly provide standlevel information in order to support forest management decisions, while national forest inventories (NFI) mainly provide statistics for reporting and policy making on regional to national scale (Tomppo et al. 2010; Vidal et al.

\begin{tabular}{l}
\hline Handling Editor: Marco Ferretti \\
\hline $\begin{array}{l}\text { Johannes Rahlf } \\
\text { johannes.rahlf@ nibio.no }\end{array}$ \\
$\bigotimes \quad \begin{array}{l}\text { Johannes Breidenbach } \\
\text { johannes.breidenbach@ nibio.no }\end{array}$
\end{tabular}

Extended author information available on the last page of the article.
2016). Traditionally, FMIs and NFIs have been completely separate activities but the increasing availability of fineresolution remotely sensed 3D data such as large-scale or even nationwide airborne laser scanning (ALS) campaigns has triggered the creation of detailed national forest resource maps, and as a consequence, the search for synergies between NFIs and FMIs (Kangas et al. 2018a).

Fine-resolution 3D data have been used in forest inventories for many years. Remotely sensed data from ALS or digital aerial photogrammetry allow accurate estimation of forest stand parameters (Rahlf et al. 2014) to support forest management decisions (Kangas et al. 2018b). In the Nordic countries, ALS is currently the most common method for the acquisition of auxiliary data in FMIs (Næsset 2014; Maltamo et al. 2021). Common steps in an ALS-based FMI are (1) manual stand delineation, (2) stratification of the stands into four or more treespecies and maturity-class-specific strata, (3) ALS data 
acquisition, (4) measurements of some hundred field sample plots systematically distributed in the strata, (5) fitting of stratum-specific linking models for timber volume and other response variables, and (6) estimation of stand-level parameters. One main outcome of FMIs is a stand map or stand list that includes stand-level information on the dominant species and the estimated timber volume.

NFIs, on the other hand, collect data for regional or national statistics over several years according to a national systematic design. Such a sampling design results in an overall larger data set of field plot measurements at the large scale but a much smaller sampling fraction than in a FMI. Nevertheless, earlier studies have explored the use of NFI sample plot data with remote sensing for standlevel estimation of forest parameters. McRoberts (2008) achieved promising results using Landsat satellite imagery to bridge strategic inventories and FMIs in Minnesota, USA. Breidenbach et al. (2018) compared unit-level and arealevel models and estimators based on NFI and digital aerial photogrammetry data. Maltamo et al. (2009) and Tuominen et al. (2014) used ALS data and Finnish angle count NFI data with or without additional fixed radius sample plot measurements to estimate stand parameters and assessed estimation accuracy. While the use of NFI plots produced acceptable estimates and improved accuracies when used together with fixed radius plots, the NFI sample plot designs caused problems for practical application.

Other approaches combining NFI and remotely sensed data focus on the creation of national forest resource maps by wall-to-wall mapping of forest parameters on nationwide scale. Early examples of such maps linked coarse optical satellite data with NFI sample plots as reference data (Tomppo 1991; Reese et al. 2003; Gjertsen 2007). In recent years, coverage with fine-resolution 3D remotely sensed data has increased drastically. On one hand, advances in soft- and hardware made it possible to compute largescale 3D information from aerial imagery by means of digital aerial photogrammetry. Such 3D data have been used to create forest resource maps covering large regions or nations (Breidenbach et al. 2016; Bohlin et al. 2017; Rahlf et al. 2017; Waser et al. 2017; Astrup et al. 2019), using NFI data as reference. On the other hand, large-scale ALS campaigns have been or are currently being conducted in several countries, mainly aiming at the creation of accurate digital terrain models. While the remotely sensed data used in these maps are often not optimized for forest analyses and varying sensors, acquisition settings and conditions lead to variation in the ALS data (Næsset 2009; Næsset and Gobakken 2008; Hill et al. 2018), the large-area coverage enables the use of a great number of NFI sample plots in the fitting of forest parameter models. Examples of forest maps based on large-scale ALS data are Nilsson et al. (2016), Monnet et al. (2016) and Nord-Larsen and Schumacher
(2012). In the following, we will denote these data sets "NFI-based maps," and the regression models that link the ALS data with NFI plot data as "NFI models." NFI-based maps typically contain forest parameters required in FMIs (Næsset 2014).

Studies on the transferability of FMI models among areas (Tompalski et al. 2019; Karjalainen et al. 2019) suggest that models linking ALS metrics with variables of interest are relatively stable in most cases and often can be transferred between different areas, but that systematic errors may occur. These results are to be expected because synthetic estimators, e.g., estimators aggregating model predictions, only have small bias, if the local condition corresponds to the condition in the population used to fit the model (Rao and Molina 2015, p. 36; Mandallaz 2013). Related to transferring models between different areas is the application of a large-scale model, as used for NFIbased maps, within a smaller area, where only a few or no sample plots are located. While error analyses for NFIbased maps have been conducted on stand scale (e.g., Nilsson et al. 2016), it has not been studied how NFI-based map estimates compare to FMI estimates. If (synthetic) stand-level estimates from NFI-based maps were similar to estimates from a traditional FMI approach, the NFIbased maps could easily be used in FMIs. The use of the NFI-based map would then allow considerable cost saving by eliminating or reducing the need for field plot measurements.

The aim of this study is to compare the performance of a model used in a NFI-based map, namely the Norwegian national forest resources map SR16, and models used in a traditional FMI in terms of accuracy of plot-level predictions and stand-level estimates of timber volume of mature spruce stands. Furthermore, we evaluate utilizing additional local sample plots in the model of the NFI-based map ("adjusted NFI model") in an attempt to improve local model accuracy.

\section{Material and methods}

\subsection{Study area}

The study area is in southeastern Norway, covering parts of the counties Innlandet and Viken (Fig. 1). A FMI was conducted within the study area and covers the municipalities Valer and Elverum. The forests are dominated by Norway spruce (Picea abies (L.) Karst.) and Scots pine (Pinus sylvestris L.), comprising 52\% and $35 \%$ of the overall timber volume, respectively. Deciduous tree species are less frequent $(13 \%$ of the overall timber volume). For the current analysis, we focus on the FMI stratum consisting of Norway spruce-dominated stands in 
the maturity classes "production forest" and "old production forest," which comprise the oldest and economically most valuable stands. For simplicity, we will refer to the stratum of interest as mature spruce forest. A description of the Norwegian maturity-class system can be found in Breidenbach et al. (2020, Section 5.3.2).

\subsection{Airborne laser scanning data}

The ALS data used in this study were acquired as part of a national program to create a fine-resolution and nationwide elevation model (Statens kartverk 2018). An available FMI (Blom Norway 2018, unpublished) had been conducted within three ALS acquisition projects (Fig. 2, Table 1). Additionally, data from other ALS acquisitions in southeastern Norway (Fig. 1) with varying sensors, point densities, and acquisition dates were used in the NFI models.

For each ALS project, ALS returns were extracted that intersected with the NFI and FMI sample plots. We used the existing national terrain model based on ALS data with a resolution of $1 \mathrm{~m}$ to subtract terrain elevation from the return elevation to obtain heights above ground, using bidirectional linear interpolation. ALS height metrics were calculated from the point clouds: mean height (zmean), height standard deviation (zsd), and height percentiles (zp05, zp10, zp20, .., zp90, zp95). Density metrics were calculated by dividing the distance between the lowest and the highest return into 10 bins with equal heights and calculating the percentage of returns above the lower bin threshold $(\mathrm{d} 2, \mathrm{~d} 3, \ldots, \mathrm{d} 10)$. We calculated these metrics for first returns $\left(*_{-}\right.$f) and for last returns $(* 1)$ without a height threshold, and with a height threshold of $2 \mathrm{~m}$ $\left(*-2 \mathrm{~m}_{-} \mathrm{f}, *-2 \mathrm{~m}_{-} \mathrm{l}\right)$. For example, the 50th height percentile of the last returns with a height threshold of $2 \mathrm{~m}$ would be abbreviated zp50_2 $\mathrm{m}_{-} \mathrm{l}$. The percentage of all returns above $2 \mathrm{~m}$ (perc_n $\_2 \mathrm{~m}$ ) served as an additional density metric.

For mapping purposes, we used $16 \times 16 \mathrm{~m}$ grid cells, that correspond approximately to the NFI and FMI plot sizes (see Sections 2.3 and 2.5). For each grid cell, we extracted the ALS returns and subtracted the terrain height. Subsequently, the same ALS metrics as for the sample plots were calculated wall-to-wall for each ALS project.

\subsection{FMI data}

Forest stand polygons were available as part of the FMI (Blom Norway 2018); they were delineated by visual interpretation of remotely sensed data and classified into five strata based on tree species, site index, and maturity class. A total of 20,427 stands with areas between 0.03 and 25 ha, covering a total area of 19,800 ha, were within the
Fig. 1 Location of the study area and the NFI plots used. Subdivisions within the study area indicate different ALS projects. The area covered by the FMI is highlighted in dark gray
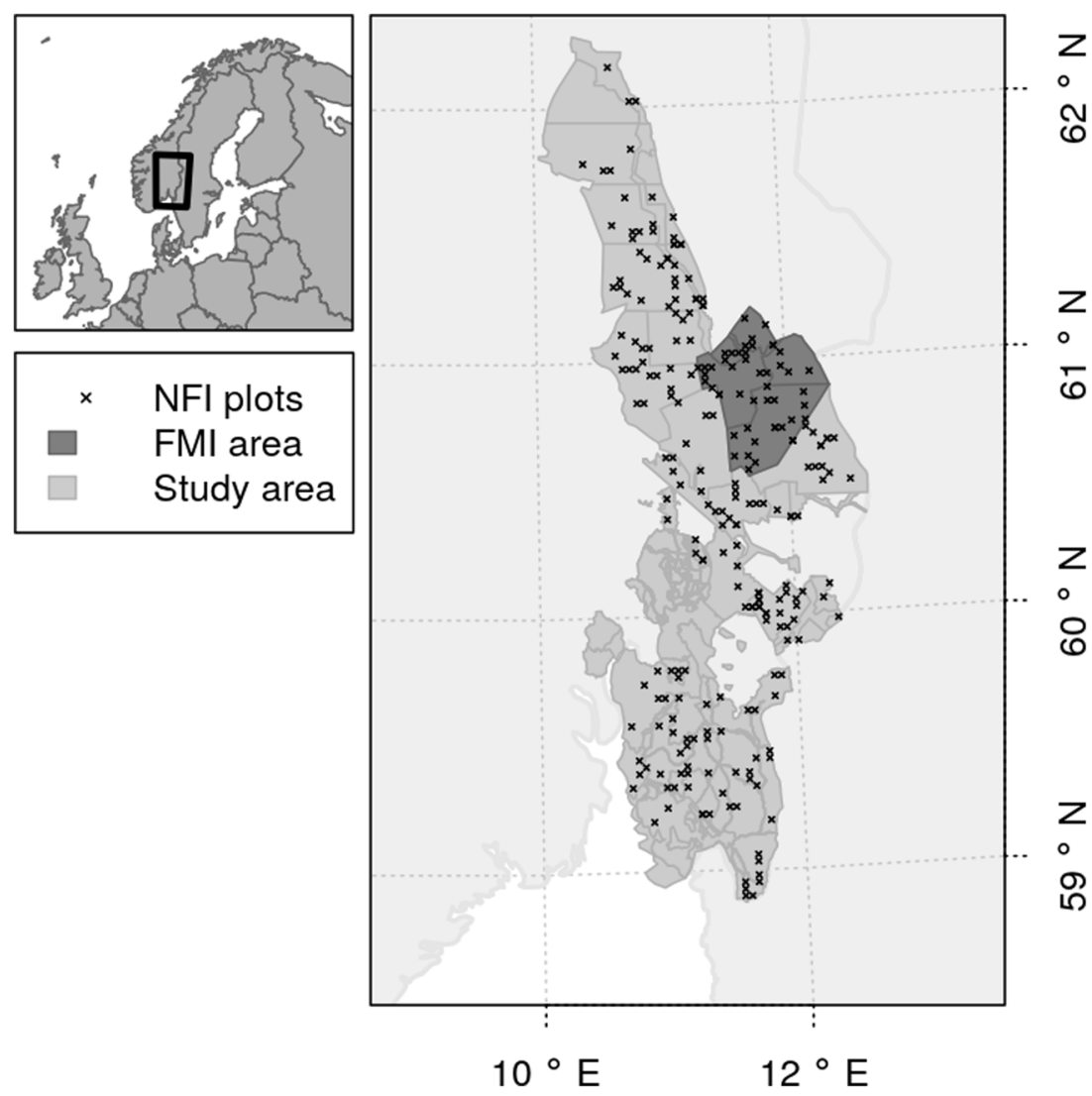
Fig. 2 Approximate locations of the NFI and FMI plots within the FMI area and stands with a detailed inventory. Subdivisions indicate different ALS projects (A-C)

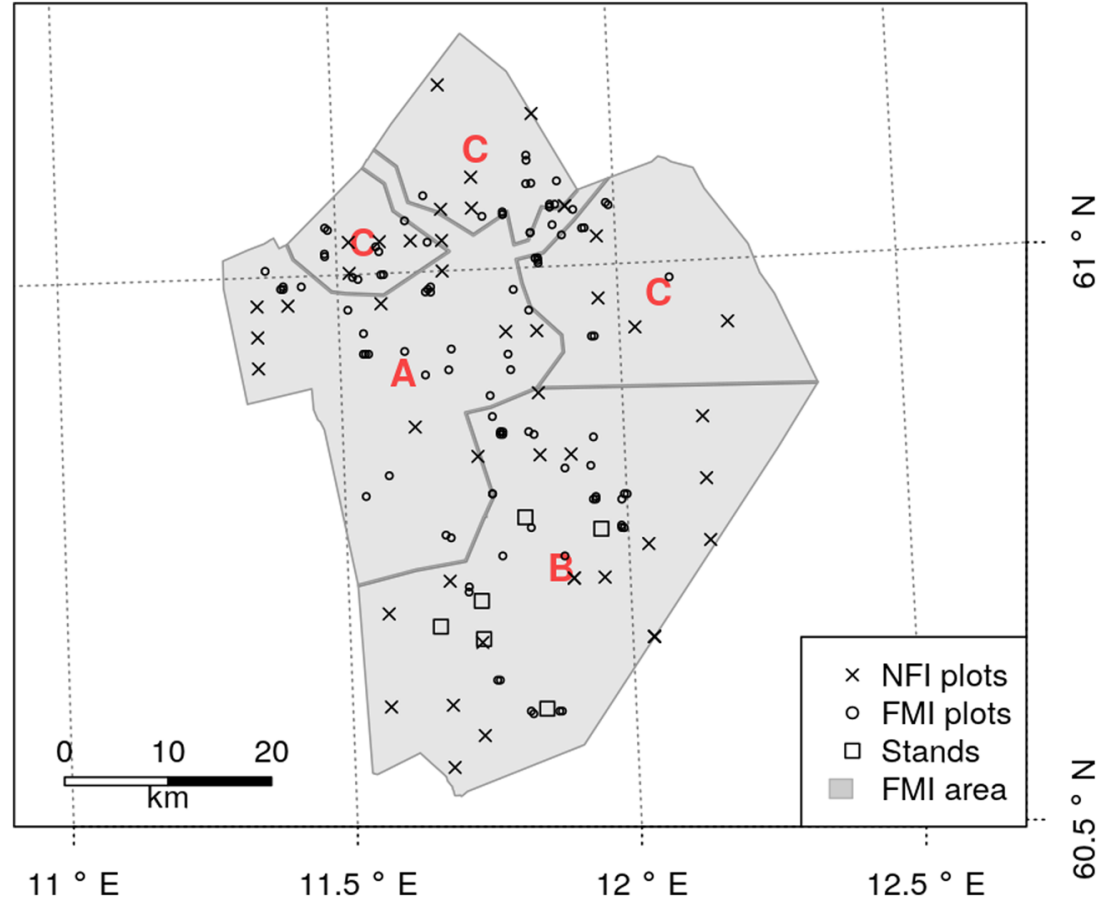

The mean timber volume of the FMI was $51 \%$ and $13 \%$ larger than the mean timber volume of the NFI plots in the FMI area and the whole study area, respectively (Table 2).

\subsection{FMI models}

FMI models were fitted following the methodology of forest management planning in Norway (Næsset 2014) which is based on the area based approach (Næsset 2002). Log-log models were fitted for each ALS project using the estimated FMI plot timber volume measurements (Section 2.3) as response and ALS metrics as explanatory variables.

$\ln v o l_{j}=\beta_{0}+\beta_{1} \ln x_{1}+\ldots+\beta_{k} \ln x_{k}+\varepsilon_{j}$,

where $\operatorname{vol}_{j}$ is the timber volume at FMI plot $j$ and $x_{1}, \ldots, x_{k}$ are the explanatory variables. To correct for transformation bias, half the model variance was added to the intercept before transforming predictions back to the original scale.

Explanatory variables for the $\log$-log models were selected using a stepwise forward and backward selection scheme informed by the Akaike information criterion (AIC) (Table 3). The algorithm was allowed a maximum of four explanatory variables in addition to the intercept to avoid overfitting.

Accuracies of the models were assessed based on leave-one-out cross-validation of the modeling data using root-mean-squared deviance (RMSD, RMSD\%) and mean deviance (MD, MD\%). 
Table 2 Summary of the plot-level timber volume measurements. SD is standard deviation and CV is coefficient of variation

\begin{tabular}{llllllll}
\hline Inventory & Year & $n$ plots & \multicolumn{2}{l}{ Timber volume $\left(m^{3} h a^{-1}\right)$} & & \\
\cline { 4 - 8 } & & & Minimum & Mean & SD & CV $(\%)$ & Maximum \\
\hline FMI & 2017 & 98 & 71 & 321 & 182 & 57 & 972 \\
NFI in FMI area & $2014-2018$ & 40 & 37 & 213 & 138 & 65 & 641 \\
NFI & $2014-2018$ & 244 & 29 & 285 & 167 & 59 & 884 \\
\hline
\end{tabular}

In the cases where models were evaluated using measured data, RMSD and MD are the same as root-meansquared error (RMSE) and mean error (ME). Here, " $R^{2}$ of Prediction" (Montgomery et al. 2012, p. 152), further referred to as $R^{2}$, is also given, allowing assessment of the variance in the predictions in relation to the variance in the population. RMSD, MD, and $R^{2}$ were defined as

$R M S D=\sqrt{\frac{1}{n} \sum_{j=1}^{n}\left(y_{j}-\hat{y}_{j}\right)^{2}}, \quad R M S D \%=\frac{R M S D}{\bar{y}} \cdot 100$,

$M D=\frac{1}{n} \sum_{j=1}^{n}\left(y_{j}-\hat{y}_{j}\right), \quad M D \%=\frac{M D}{\bar{y}} \cdot 100$,

$R^{2}=1-\frac{\sum_{j=1}^{n}\left(y_{j}-\hat{y}_{j}\right)^{2}}{\sum_{j=1}^{n}\left(y_{j}-\bar{y}\right)^{2}}$,

where $y_{j}$ is the timber volume observed at plot $j, \hat{y}_{j}$ is the back-transformed predicted timber volume at plot $j, \bar{y}_{j}$ is the mean observed timber volume of all plots, and $n$ is the total number of plots.

Across all ALS projects, the (cross-validated) RMSD was $62 \mathrm{~m}^{3} h a^{-1}$ (19\%), MD $2 \mathrm{~m}^{3} h a^{-1}$ (1\%), and $R^{2} 0.88$. Figure 3 illustrates the model fits for all three ALS projects at plot level. RMSDs, MDs, and $R^{2}$ using NFI data are given in the Results (Section 3.1).

\section{$2.5 \mathrm{NFI}$ data}

The 815 permanent sample plots of the Norwegian NFI (Breidenbach et al. 2020) in the study area were measured between 2014 and 2018 (Fig. 1). A total of 244 of the plots belonged to the mature spruce stratum (see Table 2) of which 12 were in ALS project A, 17 in B, and 13 in $\mathrm{C}$ (Figs. 1 and 2). The NFI sample plots are circular with an area of $250 \mathrm{~m}^{2}$. On the sample plots, dbh and tree species of all trees with $\mathrm{dbh} \geq 5 \mathrm{~cm}$ are registered. Tree heights are measured from approximately 10 trees per plot, which are sampled using weights based on diameter and distance to the plot center. Positions of the sample plot centers were measured using differential GPS and GLONASS.

Like for the FMI data, timber volume was estimated following the methodology of the Norwegian NFI (see Section 2.3). The timber volumes were fore- and backcasted to summer 2017, when the FMI was conducted. To do so, we calculated the yearly increment from the recent two tree-level volume predictions and multiplied the increment by the time difference which was then added to the predicted timber volume at tree level. To adjust the NFI data to the FMI protocol, trees with $\mathrm{dbh}<10 \mathrm{~cm}$ were discarded and the plots were stratified according to the FMI stratification. Single tree volumes were subsequently totaled at plot level, and estimates of timber volume per hectare were calculated.

\subsection{NFI model}

The bases for the timber volume map within the NFI-based Norwegian forest resources map SR16 (Astrup et al. 2019)

Table 3 Model parameter estimates, root-mean-squared deviance (RMSD), and mean deviance (MD) (based on leave-one-out cross-validation) of the FMI models. ALS is airborne laser scanning. ALS metrics are explained in detail in Section 2.2

\begin{tabular}{|c|c|c|c|c|c|c|c|c|c|c|}
\hline $\begin{array}{l}\text { ALS } \\
\text { project }\end{array}$ & $n$ & Explanatory variables ${ }^{\dagger}$ & $\beta_{0}$ & $\beta_{1}$ & $\beta_{2}$ & $\beta_{3}$ & $\beta_{4}$ & $\begin{array}{l}\text { RMSD } \\
(\%)\end{array}$ & $\begin{array}{l}\text { MD } \\
(\%)\end{array}$ & $R^{2}$ \\
\hline A & 32 & Intercept, zmean_f, d5_2m_f, d5_2m_l, zq20_l & 0.65 & 2.01 & -1.35 & 0.96 & -0.05 & 15 & 0 & 0.88 \\
\hline B & 29 & Intercept, zmean_1, zq10_f, zq10_1 & 2.26 & 1.70 & -0.10 & 0.15 & & 22 & 1 & 0.90 \\
\hline $\mathrm{C}$ & 37 & Intercept, zmean_f, zmean_l, d9_2m_f, d9_l & 2.62 & 1.01 & 0.55 & 0.42 & -0.31 & 20 & 1 & 0.94 \\
\hline
\end{tabular}

\footnotetext{
${ }^{\dagger} \mathrm{zmean}=$ mean return height; $\mathrm{zq}^{*}=*$ th percentile of return heights; $\mathrm{d}^{*}=$ proportion of returns above the $*$ th height bin; $* \mathrm{f}=$ only using first returns; *_l = only using last returns; * $2 \mathrm{~m}=$ applying a minimum return height threshold of $2 \mathrm{~m}$
} 

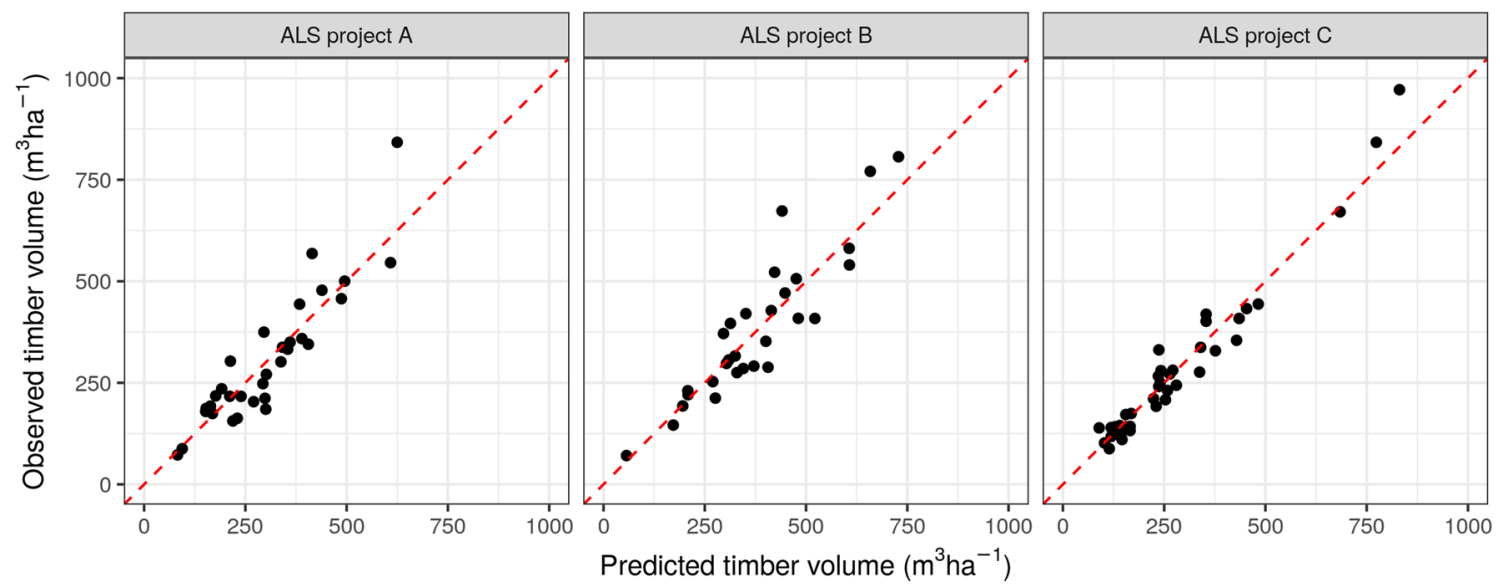

Fig. 3 Observed vs. predicted timber volume using FMI models. Predictions for the FMI plots were based on leave-one-out cross-validation

are linear mixed-effects models fitted to data from NFI sample plots of a larger region covered by available ALS data. Tree species-specific models are fitted with timber volume as the response and ALS metrics as fixed effects. The ALS metrics used in the models are mean first return height above ground and a density metric. An identifier at ALS-project level is used as random effect to address differences in the sensors and the acquisition conditions. Because the within-group variance is observed to increase linearly with volume, heteroscedasticity is modeled using a variance function.

We re-fitted a linear mixed-effects model for timber volume of mature spruce stands using the ALS and NFI data within the study area with the adjusted dbh threshold of $10 \mathrm{~cm}$. We refer to this model as the "NFI model." Fixed effects were zmean_f and zmean_f $f^{2}$, as well as perc_n_2m as a density metric. Before model fitting, 10 outliers that were likely affected by harvests were visually identified and removed by analyzing residual plots. A random effect on the ALS-project level was used for the slope of zmean_f.

The NFI model was formulated as

$$
\begin{aligned}
\operatorname{vol}_{i j}= & \beta_{0}+\left(b_{i}+\beta_{1}\right) \text { zmean }_{-} f_{i j}+\beta_{2} \text { zmean }_{-} f_{i j}^{2} \\
& +\beta_{3} \text { perc } \_\_2 m_{i j}+\varepsilon_{i j}, \\
i= & 1, \ldots, m, \quad j=1, \ldots, n_{i}, \quad b_{i} \sim N\left(0, \sigma_{b}^{2}\right), \\
& \varepsilon_{i j} \sim N\left(0, \sigma_{\varepsilon}^{2} \text { zmean }_{-} f_{i j}\right),
\end{aligned}
$$

where vol $_{i j}$ is the timber volume at sample plot $j$ in ALS project $i$. $\beta_{1}, \beta_{2}, \beta_{3}$ are the fixed-effects parameters, $b_{i}$ is the random-effect parameter, $n_{i}$ is the number of sample plots within ALS project $i, m=26$ is the number of ALS projects, $\sigma_{b}^{2}$ is the variance of the random effect, and $\sigma_{\varepsilon}^{2}$ is the residual variance. The variance function has a single variance covariate zmean_f. The model was fitted using the nlme package (Pinheiro et al. 2019) in R (R Core Team 2019).

The estimated parameters and other characteristics of the NFI model are shown in Table 4. The cross-validated RMSD of the NFI model was $21 \%$ with no systematic deviation (MD) based on all NFI sample plots and the $R^{2}$ was 0.88 . The RMSD on plot level describes the uncertainty of the NFI-based map on pixel level. The observed vs. crossvalidation-predicted timber volume is shown in Fig. 4. RMSDs, MDs, and $R^{2}$ using FMI data are given in the Results (Section 3.1).

\subsection{Adjusted NFI model: utilizing additional local sample plots for model improvement}

We attempted to improve the local accuracy of the NFI based map by extending the modeling data set of the NFI model with local sample plots. Two data sets were tested: (i) a combination of the NFI and all FMI sample plots and (ii) a combination of the NFI and a subset of FMI sample plot data. The NFI models were refitted with the extended modeling data using Eq. 5. The subset of FMI sample plots was chosen based on the value of zmean $f$. A comparison of the NFI and FMI sample plots shows the presence of relatively more plots with larger volumes in the FMI data (Table 2). Because of the correlation of

Table 4 Parameter estimates of the mixed-effects model

\begin{tabular}{llllllll}
\hline & $\beta_{0}$ & $\beta_{1}$ & $\beta_{2}$ & $\beta_{3}$ & $\sigma_{b}$ & $\sigma_{\varepsilon}$ & $b_{i}$ \\
\hline Parameter estimates & 23.73 & 19.75 & 0.98 & -63.34 & 1.39 & 17.08 & A:-0.92, B:1.45, C:-0.75 \\
\hline
\end{tabular}


Fig. 4 Observed vs. predicted timber volume $\left(\mathrm{m}^{3} h \mathrm{a}^{-1}\right)$ at the NFI plots using the NFI model. Predictions are based on leave-one-out cross-validation

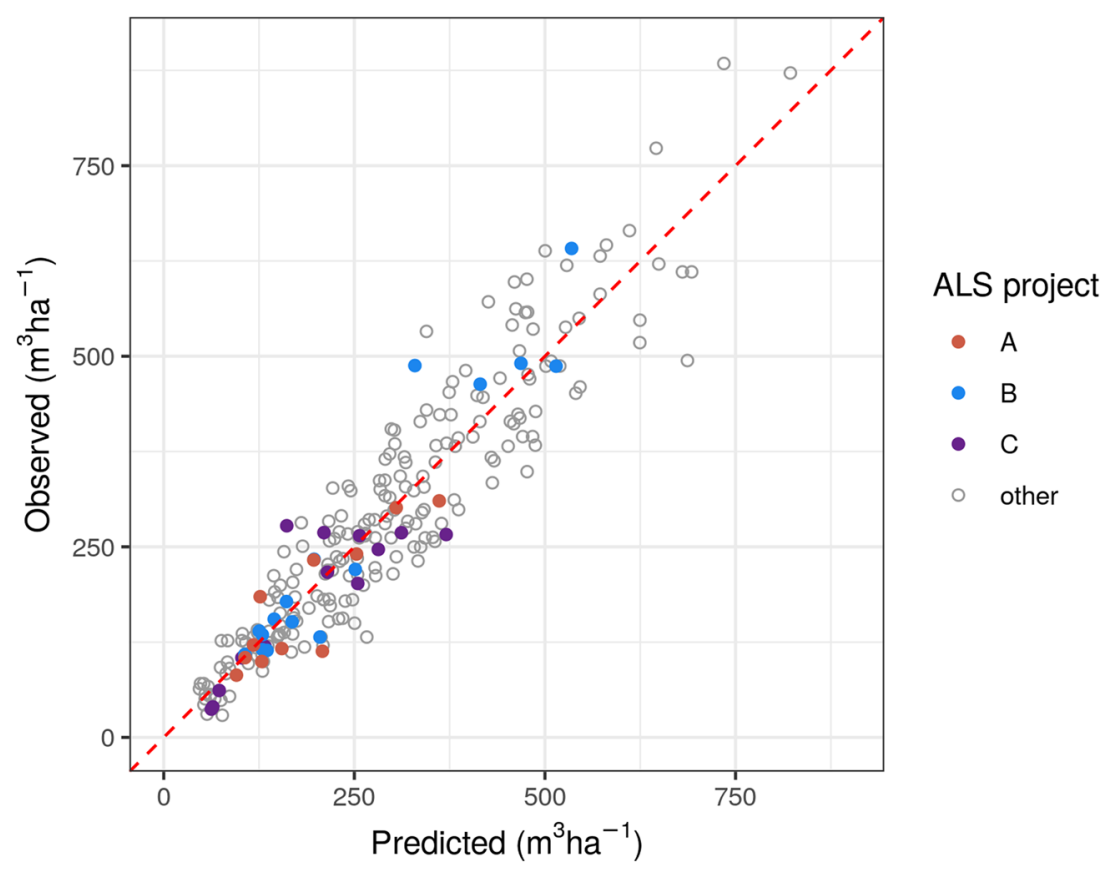

zmean_f and timber volume, the FMI sample plots were sorted based on the value of zmean_f, and a number of plots were chosen from the top of this list, i.e., plots with the largest values of zmean_f. By iterative testing and evaluating the improvement, the number of FMI sample plots selected to be combined with the NFI data was set to 7 per ALS project. Predictions of timber volume at the FMI sample plots for the calculation of accuracy measures were obtained using leave-one-out cross-validation for sample plots that were used in the modeling data. In the following, we refer to the resulting models as "adjusted NFI models."

\subsection{Comparison of the FMI and NFI models using stand-level estimates}

Using the fitted models, timber volume was predicted for all $16 \times 16 \mathrm{~m}$ cells of a grid covering the study area. To obtain synthetic estimates of stand-level timber volume, we averaged the predictions of the grid cells with a center within the stands. To reduce the computational cost, we randomly selected 200 FMI stands per ALS project. Stands were required to have a minimum area of 1 ha. An areato-perimeter ratio can describe the compactness of stands. Only stands with a ratio $\sqrt{\text { area }} /$ perimeter $>0.2$. were selected to reduce the edge effect of stand borders on the resulting estimates. We compared the synthetic stand-level estimates of the FMI models with those of the NFI models using RMSD, MD, and $R^{2}$ with $y_{j}$ and $\hat{y}_{j}$ as FMI and NFI model synthetic estimate, respectively.

\subsection{Comparison with an independent forest inventory}

As basis for a comparison with independent data, 61 sample plots in six forest stands were measured in ALS project B in 2018. The stands were selected from the delineated forest stand polygons with areas between 1.5 and 5.5 ha and a ratio $\sqrt{\text { area }} /$ perimeter $>0.2$ (see Section 2.8 ). Ten to 11 sample plots were randomly selected from nodes of a $20 \times 20 \mathrm{~m}$ grid intersecting with the stand boundaries. After the removal of one plot that coincided with forest road, one stand had nine sample plots, resulting in a total of 60 sample plots for the comparison.

In the field, plot center positions were measured using handheld GPS devices. The plots were circular with an area of $250 \mathrm{~m}^{2}$ and were measured according to the NFI protocol (Section 2.5). The tree measurements were adjusted to the FMI protocol by discarding trees with $\mathrm{dbh}<10 \mathrm{~cm}$, and single tree volumes were estimated following the methodology of the Norwegian NFI (Breidenbach et al. 2020). Individual tree volumes were totaled at plot level, and per hectare volume was calculated. Subsequently, stand-level estimates were obtained by averaging plot-level measurements (see Rahlf et al. 2014). Stand-level estimates based on these measurements are referred to as direct estimates. Direct estimates were treated as an observation.

Plot-level measurements ranged from 84 to $646 \mathrm{~m}^{3} \mathrm{ha}^{-1}$ and stand-level direct estimates from 154 to $380 \mathrm{~m}^{3} \mathrm{ha}^{-1}$. ALS data were clipped to the plot boundaries and plot-level 
timber volume was predicted using the area based approach (see Section 2.4) for each plot. RMSD, MD, and $R^{2}$ were calculated using Eqs. 3-4 by substituting $y_{j}$ with the direct estimate and $\hat{y}_{j}$ with the average prediction for the plots within a stand using the FMI, NFI, or adjusted NFI model. It may be noted that there is no sampling-related uncertainty in the direct estimate due to this procedure.

\section{Results}

\subsection{Comparison of FMI and NFI predictions and estimates}

We validated the FMI models using NFI plots in the FMI area resulting in a RMSD and MD of 26\% $\left(56 \mathrm{~m}^{3} \mathrm{ha}^{-1}\right)$ and $-4 \%\left(-8 m^{3} h a^{-1}\right)$, respectively $\left(R^{2}=0.83\right)$. Similarly, the NFI model was validated using FMI plots, resulting in an RMSD and MD of 27\% $\left(86 \mathrm{~m}^{3} \mathrm{ha}^{-1}\right)$ and $10 \%$ $\left(33 \mathrm{~m}^{3} h \mathrm{a}^{-1}\right)$, respectively $\left(R^{2}=0.78\right)$ (Table 5). The NFI model showed a slight tendency to underpredict timber volume for FMI plots with timber volume $>350 \mathrm{~m}^{3} \mathrm{ha}^{-1}$, which was mostly visible in ALS project B but less so in ALS projects $\mathrm{A}$ and $\mathrm{C}$ (Fig. 5 a).

To analyze if the NFI-based model could be improved by using additional local sample plots, we fitted models based on a combination of the NFI data and either all or a subset of the FMI data (see Section 2.7). Models fit to either of the combinations of NFI and FMI data resulted in decreased RMSDs and MDs in all ALS projects compared to the NFI model (Table 5, Fig. 5), when using FMI data for validation. The largest improvements of RMSDs were achieved when adding all FMI sample plots to the modeling data. The RMSD decreased by 3 and MD by 6 percentage points, nearly reducing the systematic error to a third of the MD of the NFI model. The RMSD of the adjusted NFI model, where only a subset of the FMI sample plots was added to the NFI data, had similar properties as the model using all NFI and FMI plots, with even smaller MDs in ALS projects $\mathrm{A}$ and $\mathrm{C}$.

We compared synthetic estimates of the FMI models, the NFI model, and the improved NFI models for a sub-sample of forest stands in the FMI area. As for the predictions at plot level, estimates of the NFI model tended to be smaller than estimates of the local FMI models. For stands with small timber volume, the NFI model produced generally larger estimates. On average, this resulted in a MD of $8 \%$. Estimates deviated least in ALS project $\mathrm{C}$ and most in A, regardless of the combination of sample plot data used for fitting the NFI model (Table 6).

The addition of local sample plots to the NFI data for the model fit reduced the differences between estimates based on the NFI and FMI models, resulting in a smaller RMSD and especially smaller MD of the adjusted NFI models, compared to the original NFI model. While the largest reduction was achieved when using all FMI sample plots, the reduction for the adjusted NFI model with 7 additional FMI sample plots was similar, with differences in RMSD and MD of 0-1 percentage points. The smaller deviation of the estimates of the adjusted NFI models from the estimates of the FMI models can be seen in Fig. 6 .

\subsection{Comparison with independent data}

The FMI model, the NFI model, and the adjusted NFI model predictions were validated using an independent forest inventory in ALS project B. Because the adjusted NFI model fitted with a subset of FMI plots was shown to be

Table 5 Differences between NFI model predictions and measurements at the FMI sample plots. Values are based on independent validation for NFI data and cross-validation for FMI data. ALS is airborne laser scanning, RMSD is root-mean-squared deviance, and MD is mean deviance

\begin{tabular}{llllrr}
\hline Modeling data & ALS project & RMSD $\left(m^{3} h a^{-1}\right)$ & RMSD\% & MD $\left(m^{3} h a^{-1}\right)$ & MD\% \\
\hline NFI & ALS project A & 83.14 & 27 & 30.79 & 0.73 \\
NFI & ALS project B & 96.56 & 25 & 46.08 & 10 \\
NFI & ALS project C & 78.38 & 27 & 25.24 & 12 \\
NFI & total & 85.65 & 27 & 33.22 & 9 \\
NFI \& FMI & ALS project A & 76.69 & 25 & 11.25 & 10 \\
NFI \& FMI & ALS project B & 84.11 & 22 & 16.60 & 4 \\
NFI \& FMI & ALS project C & 69.56 & 24 & 8.46 & 0.83 \\
NFI \& FMI & total & 76.43 & 24 & 11.78 & 0.78 \\
NFI \& top 7 FMI & ALS project A & 78.25 & 26 & 9.61 & 3 \\
NFI \& top 7 FMI & ALS project B & 86.55 & 23 & 27.28 & 4 \\
NFI \& top 7 FMI & ALS project C & 69.70 & 24 & 7.11 & 3 \\
NFI \& top 7 FMI & total & 77.78 & 24 & 13.90 & 0.87 \\
\hline
\end{tabular}


Fig. 5 Observed vs. predicted timber volume $\left(\mathrm{m}^{3} h \mathrm{a}^{-1}\right)$ at the FMI sample plots; predictions derived from the NFI model based on a NFI data, b NFI and all FMI data, and $\mathbf{c}$ NFI data and the 7 FMI sample plots with the largest zmean_f
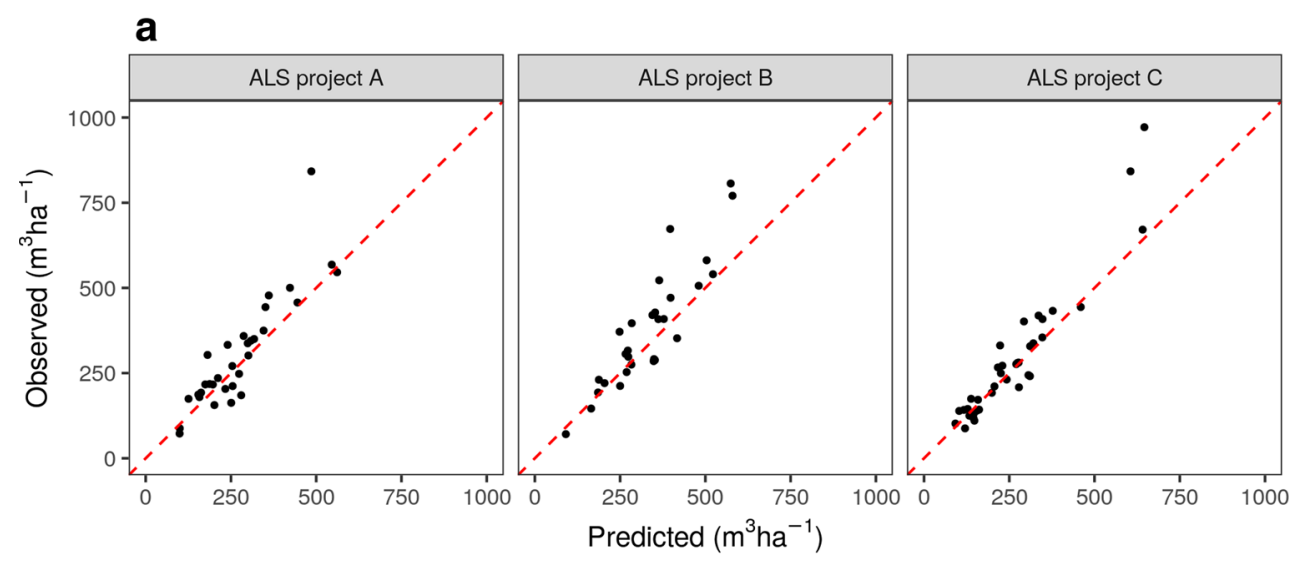

b
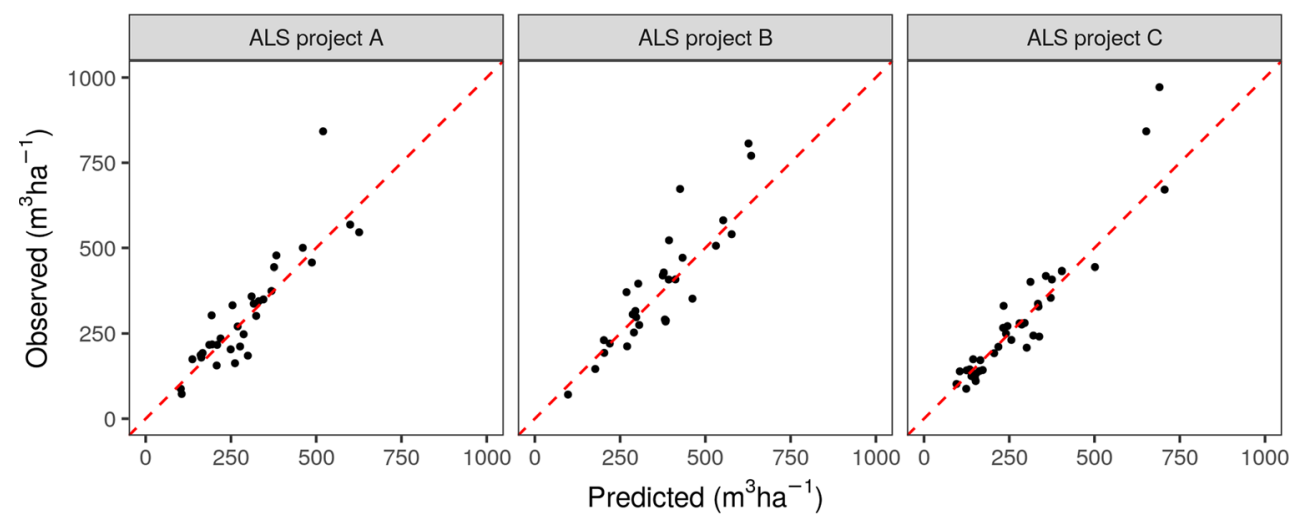

C
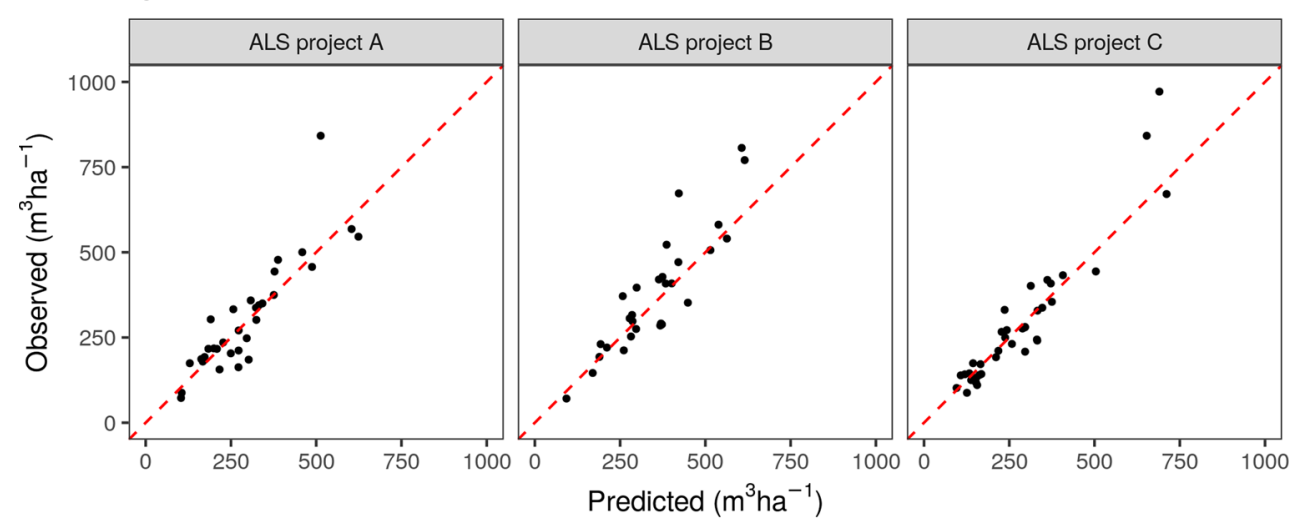

similarly accurate as the adjusted NFI model fitted with all NFI plots (Section 3.1), only the former was used in this analysis. Of the three models, the NFI model performed best at stand and at plot level (Fig. 7). At plot level, the NFI model and the adjusted NFI model produced smaller RMSDs than the FMI model (Table 7). Similar results were obtained at stand level, when the sample plot measurements and predictions were averaged for all plots within each of the 6 stands; RMSDs and MDs were smallest for the NFI and adjusted NFI model prediction. RMSDs were smaller at stand level than at plot level, while MDs had similar values.

\section{Discussion}

We compared the accuracies of a NFI model, as it is used in a NFI-based map linking ALS data and NFI sample plots, and local FMI models for timber volume of mature spruce 
Table 6 Differences between synthetic stand estimates of the FMI models and the NFI models based on 200 randomly selected stands. ALS is airborne laser scanning, RMSD is root-mean-squared deviance, and MD is mean deviance

\begin{tabular}{|c|c|c|c|c|c|}
\hline Modeling data & ALS project & $\operatorname{RMSD}\left(m^{3} h a^{-1}\right)$ & RMSD \% & $\operatorname{MD}\left(m^{3} h a^{-1}\right)$ & $\mathrm{MD} \%$ \\
\hline NFI & A & 40.25 & 15 & 23.67 & 9 \\
\hline NFI & B & 37.55 & 12 & 25.95 & 8 \\
\hline NFI & $\mathrm{C}$ & 22.83 & 10 & 15.72 & 7 \\
\hline NFI & All & 34.60 & 13 & 21.86 & 8 \\
\hline NFI \& FMI & A & 32.56 & 12 & 6.35 & 2 \\
\hline NFI \& FMI & B & 24.75 & 8 & 1.68 & 1 \\
\hline NFI \& FMI & $\mathrm{C}$ & 13.75 & 6 & 2.90 & 1 \\
\hline NFI \& FMI & All & 25.16 & 9 & 3.71 & 1 \\
\hline NFI \& top 7 FMI & A & 32.91 & 12 & 4.22 & 2 \\
\hline NFI \& top 7 FMI & B & 27.15 & 9 & 10.85 & 4 \\
\hline NFI \& top 7 FMI & $\mathrm{C}$ & 13.91 & 6 & 0.57 & 0 \\
\hline NFI \& top 7 FMI & All & 26.14 & 10 & 5.21 & 2 \\
\hline
\end{tabular}

forest. The accuracy of the NFI model was similar to that of the FMI models at plot and stand level. The NFI model was slightly more accurate than the FMI models, when an independent data set was used for validation. Here, the NFI model also showed a smaller systematic error and was able to explain a larger part of the variation than the FMI and the adjusted NFI models.

In a direct comparison of stand-level estimates, differences between the FMI and NFI models could be observed but it is unknown whether the FMI or NFI models are closer to reality. However, the differences between the FMI and NFI models were relatively small and had the same magnitudes as typical stand-level RMSDs of ALS models (Næsset et al. 2004). While no clear improvement of the NFI model accuracy could be observed when using additional local sample plots, it reduced the deviations of stand-level estimates based on the NFI model and the FMI models, making the model estimates of the NFI model more similar to the estimates of the FMI model.

MDs of the NFI model at plot level, as well as the RMSD of the estimates of the stands with validation inventory, were in line with previously reported RMSDs for ALS data (Næsset et al. 2004; Rahlf et al. 2014). Other studies on NFI-based maps for timber volume using ALS data reported similar or lower plot-level accuracies (Nord-Larsen and Schumacher 2012; Monnet et al. 2016; Nilsson et al. 2016). Analyzing the use of NFI plots in ALS-based forest management inventories, Maltamo et al. (2009) reported a larger stand-level RMSD of $19.66 \%$ and a similar MD of $-1.13 \%$, compared to the NFI model accuracies.

Testing the application of a regional model to smaller areas, Noordermeer et al. (2019) fitted local and regional multiplicative regression models using data from multiple FMIs. Accuracies for timber volume in productive mature forests were slightly higher for local than for regional models with RMSDs similar to our study. Tompalski et al. (2019) analyzed the transferability of ALS models by predicting forest parameters using different ALS data within the same study area in Canada. Unlike our findings, they reported only minor changes in RMSD and MD for ordinary least square models on plot level using cross-validation. However, differences in the ALS data were simulated by reducing point densities, which has been reported to have only limited effects on model accuracies (Gobakken and Næsset 2007; Jakubowski et al. 2013).

We used two approaches to compare accuracies of the models: Using the training data of the other model as validation data with cross-validation for the additional sample plots of the adjusted NFI models, and using an independent forest inventory as reference data set. The independent forest inventory allowed a comparison of accuracies based on the same reference data. Since the independent forest inventory was located in only one ALS project, the use of the FMI data served to assess differences in the NFI model accuracies between the ALS projects. A reason for the differences between accuracies obtained with the two approaches might be the distribution of the response variable in the data. While the measured volumes of the independent forest inventory vary around the center of the distribution of timber volume of the NFI data, the FMI sample plots show a larger range, extending over the maximum timber volume of the NFI sample plots. The largest difference between the model validation using crossvalidation and an independent forest inventory was observed 
Fig. 6 Comparison of synthetic stand-level timber volume estimates $\left(m^{3} h a^{-1}\right)$ resulting from the FMI and NFI models. NFI model estimates are derived from models (ref) based on a NFI data, $\mathbf{b}$ NFI and all FMI data, and $\mathbf{c}$ NFI data and the 7 FMI sample plots with the largest zmean_f
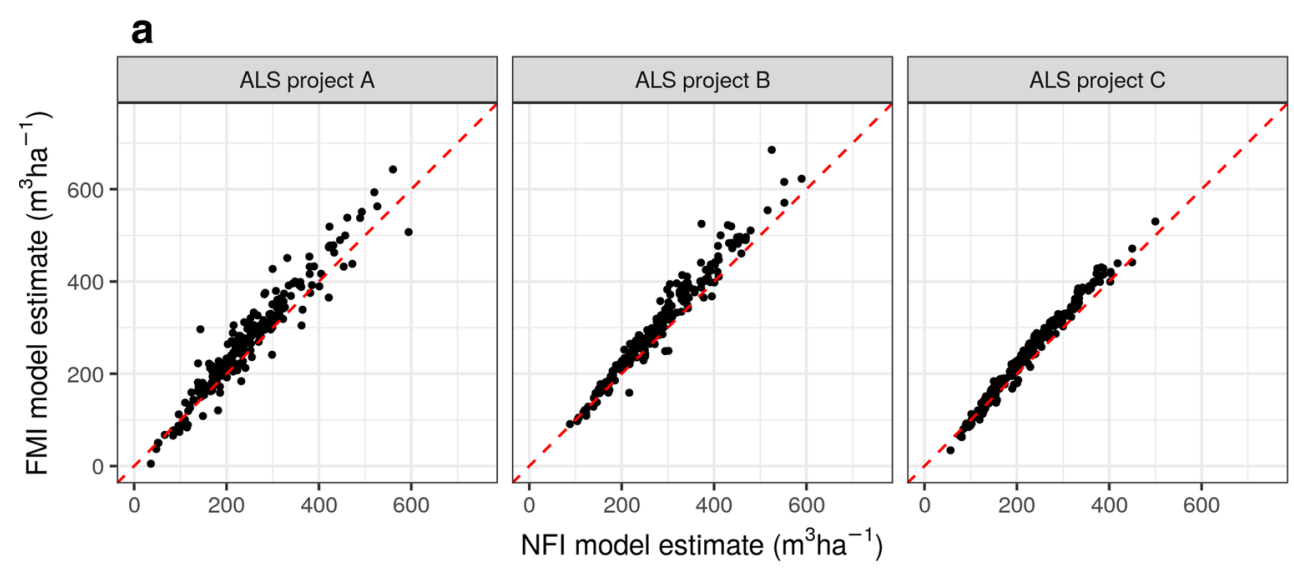

b
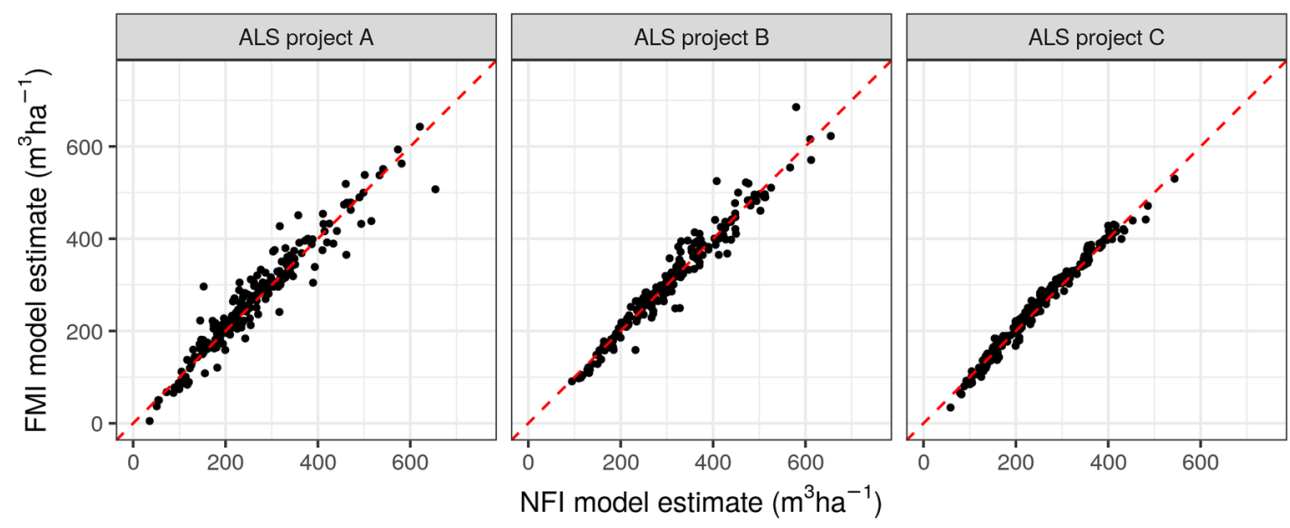

C
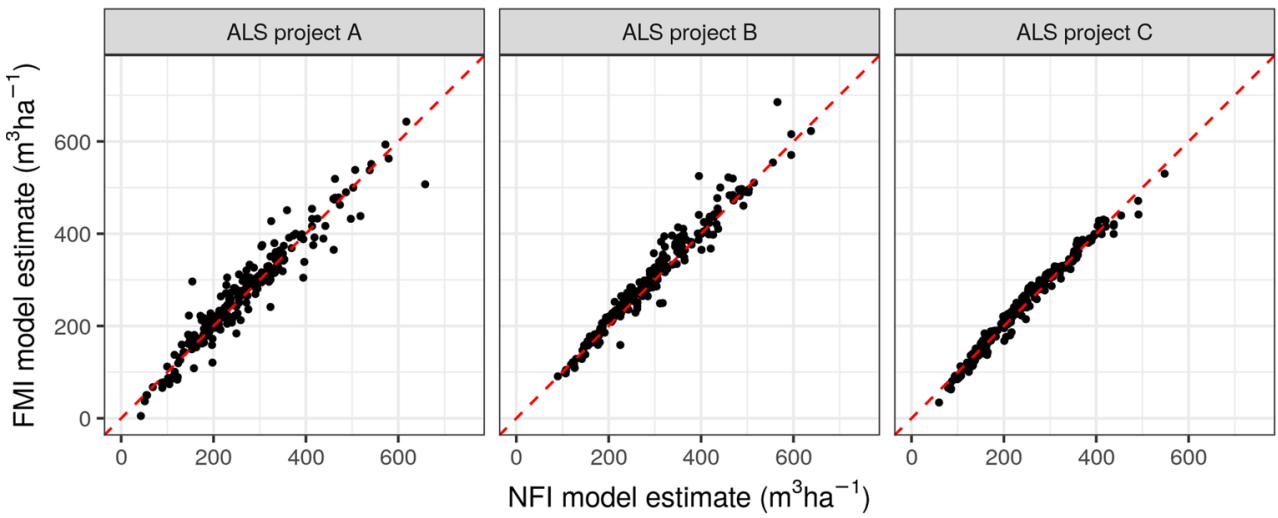

in the MD value. While these differences could be observed, both validation approaches revealed in general the same tendencies.

The validation of the NFI-based map in this study is based on the comparison with a single FMI across three ALS projects. As the differences in accuracies of the NFI model between the ALS projects suggest, an exhaustive analysis of differences between NFI and FMI accuracies would need to include multiple FMIs from different regions. Similarly, the interpretation of stand-level accuracies should therefore be carried out carefully. Stand-level accuracies in this study are based on 60 plots within six forest stands. However, even though estimation of stand-level parameters is the aim of remote sensing applications in FMIs, the analysis of plot-level accuracy is common in FMI research studies (Næsset 2014). In addition, the increase of accuracy when aggregating plot-level predictions at stand-level is in line with previous studies (Rahlf et al. 2014; Bohlin et al. 2017).

To analyze the influence of a few additional FMI plots on the NFI model, plots were selected based on their value of zmean_f. The result showed that these plots 

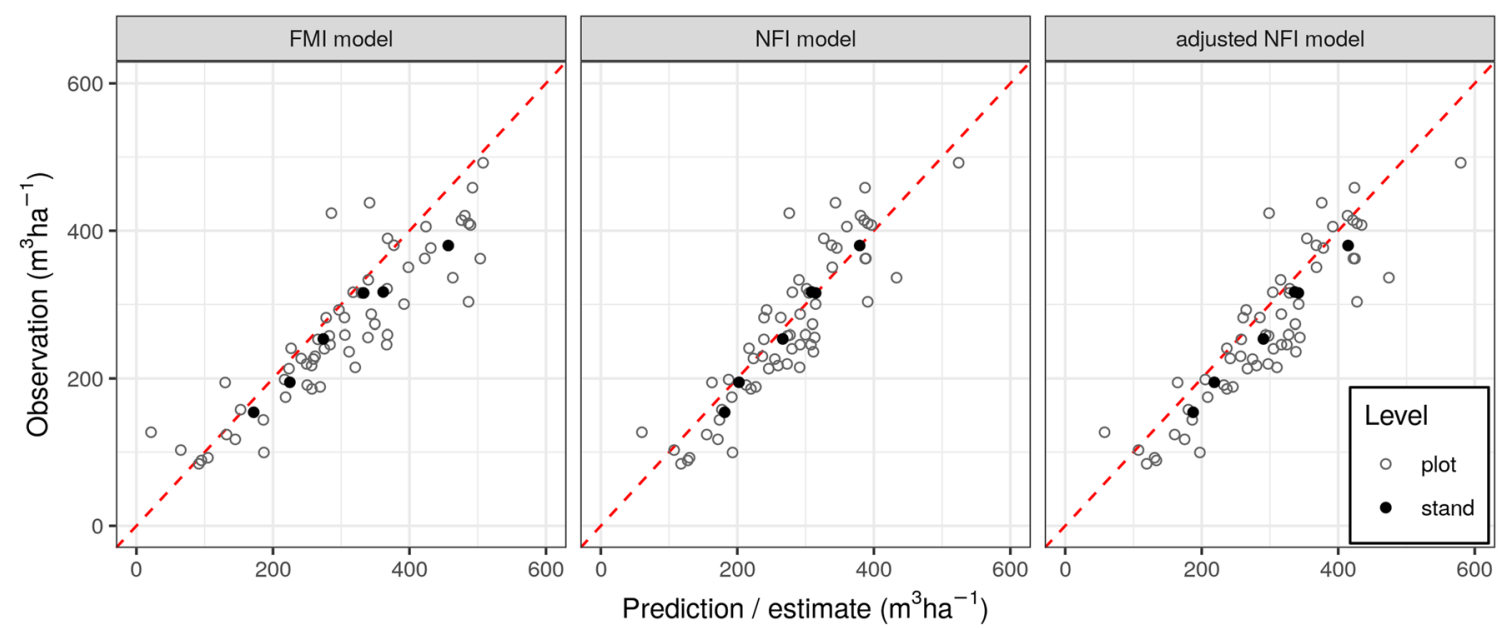

Fig. 7 Comparison of plot-level predictions and stand-level estimates to an independent forest inventory in ALS project B

slightly improved the NFI model accuracy and reduced the systematic error only for plot-level predictions when FMI data were used for validation, and the improvement differed between the ALS projects. A reason might be non-optimal selection of the local plots. Methods based on sample distributions and local conditions (Grafström et al. 2012) could be considered to improve the sample plot selection.

In this study, time differences in the data were relatively small. However, in the case of large time differences between the acquisition of remotely sensed data and the field campaign for local model adjustment, map predictions would need to be updated to avoid the introduction of bias. Besides newly available remotely sensed data, growth modeling could be used for updating. The shelf life of ALS data is expected to be longer than 10 years (McRoberts et al. 2018), longer than traditional inventory cycles of FMIs (Maltamo et al. 2021). While we used solely Norwegian data in this case study, we assume the results to be comparable in countries where environmental conditions, forest management, and inventory systems are similar.

This study provides a first analysis of the use of predictions from NFI-based maps in FMIs. We concentrated on mature spruce stands, because this stratum includes the most valuable stands and is of the highest interest for forest managers. Further work will need to explore the application of NFI-based maps in FMIs covering all development classes and also other tree species. Additionally, more parameters, e.g., stem numbers or mean tree height, need to be tested for use in an operational FMI.

In conclusion, the presented comparison shows that estimates using a NFI-based map can be similar to or more accurate than estimates from a FMI. The similar accuracies indicate that NFI-based maps can directly be used in FMIs for timber volume estimation in mature spruce stands, leading to potentially large cost savings with only small, if any, losses in accuracy. The addition of local sample

Table 7 Differences between plot and stand-level estimates of the NFI and FMI models and direct estimates of an independent inventory. RMSD is root-mean-squared deviance and MD is mean deviance

\begin{tabular}{lllllll}
\hline Level & Model & $n$ & RMSD $\left(m^{3} h a^{-1}\right)$ & RMSD\% & MD $\left(m^{3} h a^{-1}\right)$ & MD\% \\
\hline Plot & FMI model & 60 & 65 & 24 & -34 & -13 \\
Plot & NFI model & 60 & 48 & 18 & -7 & 0.59 \\
Plot & Adjusted NFI model & 60 & 55 & 21 & -29 & 0.78 \\
Stand & FMI model & 6 & 40 & 15 & -34 & -11 \\
Stand & NFI model & 6 & 13 & 5 & -6 & -13 \\
Stand & Adjusted NFI model & 6 & 30 & 11 & -29 & -2 \\
\hline
\end{tabular}


plots when fitting an NFI model did not clearly improve the model accuracy.

Funding Open access funding provided by Norwegian Institute of Bioeconomy Research. This study was supported by the Norwegian Forest Development Fund (Utviklingsfondet for skogbruket) under contracts \#16/66234-3 and \#19/42118-6, the Forest Initiative Fund (Skogtiltaksfondet) under contract \#B-2016-45, and the Norwegian Institute of Bioeconomy Research.

Open Access This article is licensed under a Creative Commons Attribution 4.0 International License, which permits use, sharing, adaptation, distribution and reproduction in any medium or format, as long as you give appropriate credit to the original author(s) and the source, provide a link to the Creative Commons licence, and indicate if changes were made. The images or other third party material in this article are included in the article's Creative Commons licence, unless indicated otherwise in a credit line to the material. If material is not included in the article's Creative Commons licence and your intended use is not permitted by statutory regulation or exceeds the permitted use, you will need to obtain permission directly from the copyright holder. To view a copy of this licence, visit http://creativecommons. org/licenses/by/4.0/.

Acknowledgments The authors are grateful to the anonymous reviewers whose comments greatly helped to improve the clarity and precision of the paper. We thank Glommen-Mjøsen Skog SA, for the provision of FMI data.

\section{References}

Astrup R, Rahlf J, Bjørkelo K, Debella-Gilo M, Gjertsen AK, Breidenbach J (2019) Forest information at multiple scales: development, evaluation and application of the Norwegian forest resources map SR16. Scand J Forest Res 34:484-496

Blom Norway AS (2018) Beregning av skogvariable basert på laserdata i elverum-våler 2018 [calculation of forest parameter based on als data in elverum-våler 2018]. techreport

Bohlin J, Bohlin I, Jonzén J, Nilsson M (2017) Mapping forest attributes using data from stereophotogrammetry of aerial images and field data from the national forest inventory. Silva Fenn 51:1-18

Braastad H (1966) Volume tables for birch. Meddelelser fra det Norske Skogforsoksvesen 21:23

Brantseg A (1967) Volume functions and tables for Scots pine. South Norway. (In Norwegian with English summary). Meddr Norske Skogfors Ves, pp 695-739

Breidenbach J, McRoberts RE, Astrup R (2016) Empirical coverage of model-based variance estimators for remote sensing assisted estimation of stand-level timber volume. Remote Sens Environ 173:274-281

Breidenbach J, Magnussen S, Rahlf J, Astrup R (2018) Unit-level and area-level small area estimation under heteroscedasticity using digital aerial photogrammetry data. Remote Sens Environ 212:199-211

Breidenbach J, Granhus A, Hylen G, Eriksen R, Astrup R (2020) A century of national forest inventory in Norway - informing past, present, and future decisions. Forest Ecosys 7:1-19

Gjertsen AK (2007) Accuracy of forest mapping based on Landsat TM data and a kNN-based method. Remote Sens Environ 110:420430

Gobakken T, Næsset E (2007) Assessing effects of laser point density on biophysical stand properties derived from airborne laser scanner data in mature forest. In: ISPRS Workshop on laser scanning, vol 200, pp 12-14

Grafström A, Lundström NL, Schelin L (2012) Spatially balanced sampling through the pivotal method. Biometrics 68:514-520

Hill A, Buddenbaum H, Mandallaz D (2018) Combining canopy height and tree species map information for large-scale timber volume estimations under strong heterogeneity of auxiliary data and variable sample plot sizes. Eur J For Res 137:489-505

Jakubowski MK, Guo Q, Kelly M (2013) Tradeoffs between lidar pulse density and forest measurement accuracy. Remote Sens Environ 130:245-253

Kangas A, Astrup R, Breidenbach J, Fridman J, Gobakken T, Korhonen KT, Maltamo M, Nilsson M, Nord-Larsen T, Næsset E, Olsson H (2018a) Remote sensing and forest inventories in Nordic countries - roadmap for the future. Scand J Forest Res 33:397-412

Kangas A, Gobakken T, Puliti S, Hauglin M, Næsset E (2018b) Value of airborne laser scanning and digital aerial photogrammetry data in forest decision making. Silva Fenn 52:9923

Karjalainen T, Korhonen L, Packalen P, Maltamo M (2019) The transferability of airborne laser scanning based tree-level models between different inventory areas. Can J For Res 49:228-236

Maltamo M, Packalén P, Suvanto A, Korhonen K, Mehtätalo L, Hyvönen P (2009) Combining ALS and NFI training data for forest management planning: a case study in Kuortane, Western Finland. Eur J For Res 128:305-317

Maltamo M, Packalen P, Kangas A (2021) From comprehensive field inventories to remotely sensed wall-to-wall stand attribute data a brief history of management inventories in the nordic countries. Can J For Res 51:257-266

Mandallaz D (2013) Design-based properties of some small-area estimators in forest inventory with two-phase sampling. Can J For Res 43:441-449

McRoberts RE (2008) Using satellite imagery and the k-nearest neighbors technique as a bridge between strategic and management forest inventories. Remote Sens Environ 112:2212-2221

McRoberts RE, Chen Q, Gormanson DD, Walters BF (2018) The shelf-life of airborne laser scanning data for enhancing forest inventory inferences. Remote Sens Environ 206:254-259

Monnet J, Ginzler C, Clivaz J (2016) Wide-area mapping of forest with national airborne laser scanning and field inventory datasets. ISPRS-international Archives of the Photogrammetry. Remote Sens Spat Inf Sci XLI:727-731

Montgomery DC, Peck EA, Vining GG (2012) Introduction to linear regression analysis, vol 821 . Wiley

Næsset E (2002) Predicting forest stand characteristics with airborne scanning laser using a practical two-stage procedure and field data. Remote Sens Environ 80:88-99

Næsset E (2009) Effects of different sensors, flying altitudes, and pulse repetition frequencies on forest canopy metrics and biophysical stand properties derived from small-footprint airborne laser data. Remote Sens Environ 113:148-159

Næsset E (2014) Area-based inventory in Norway-from innovation to an operational reality. In: Forestry applications of airborne laser scanning. Springer, pp 215-240

Næsset E, Gobakken T (2008) Estimation of above-and below-ground biomass across regions of the boreal forest zone using airborne laser. Remote Sens Environ 112:3079-3090

Næsset E, Gobakken T, Holmgren J, Hyyppä H, Hyyppä J, Maltamo M, Nilsson M, Olsson H, Persson Å, Söderman U (2004) Laser scanning of forest resources: the Nordic experience. Scand J For Res 19:482-499

Nilsson M, Nordkvist K, Jonzén J, Lindgren N, Axensten P, Wallerman J, Egberth M, Larsson S, Nilsson L, Eriksson J, Olsson H (2016) A nationwide forest attribute map of Sweden predicted using airborne laser scanning data and field data from the national forest inventory. Remote Sens Environ:447-454 
Noordermeer L, Bollandsås OM, Ørka HO, Næsset E, Gobakken T (2019) Comparing the accuracies of forest attributes predicted from airborne laser scanning and digital aerial photogrammetry in operational forest inventories. Remote Sens Environ 226:26-37

Nord-Larsen T, Schumacher J (2012) Estimation of forest resources from a country wide laser scanning survey and national forest inventory data. Remote Sens Environ 119:148-157

Pinheiro J, Bates D, DebRoy S, Sarkar D, R Core Team (2019) nlme: linear and nonlinear mixed effects models. https://CRAN. R-project.org/package $=$ nlme, $r$ package version 3.1-141

R Core Team (2019) R: a language and environment for statistical computing. R Foundation for Statistical Computing, Vienna, Austria. https://www.R-project.org/

Rahlf J, Breidenbach J, Solberg S, Næsset E, Astrup R (2014) Comparison of four types of 3D data for timber volume estimation. Remote Sens Environ 155:325-333

Rahlf J, Breidenbach J, Solberg S, Næsset E, Astrup R (2017) Digital aerial photogrammetry can efficiently support large-area forest inventories in Norway. Forest Int J Forest Res 90:710-718

Rao JNK, Molina I (2015) Small area estimation, 2nd edn. Wiley

Reese H, Nilsson M, Pahlén TG, Hagner O, Joyce S, Tingelöf U, Egberth M, Olsson H (2003) Countrywide estimates of forest variables using satellite data and field data from the national forest inventory. AMBIO J Human Environ 32:542-548
Statens kartverk (2018) Produktspesifikasjon fkb-laser versjon 3.0. techreport. https://register.geonorge.no/data/documents/Produktspesifi kasjoner_FKB-Laser_v1_fkb-laser-v30-2018-01-01_.pdf

Tompalski P, White JC, Coops NC, Wulder MA (2019) Demonstrating the transferability of forest inventory attribute models derived using airborne laser scanning data. Remote Sens Environ 227:110 124

Tomppo E (1991) Satellite image-based national forest inventory of Finland. Int Arch Photogram Remote Sens 28:419-424

Tomppo E, Gschwantner T, Lawrence M, McRoberts RE (eds) (2010) National forest inventories. Springer, Netherlands

Tuominen S, Pitkänen J, Balazs A, Korhonen KT, Hyvönen P, Muinonen E et al (2014) NFI plots as complementary reference data in forest inventory based on airborne laser scanning and aerial photography in Finland. Silva Fennica 48:1-20

Vestjordet E (1967) Funksjoner og tabeller for kubering av stående gran [functions and tables for volume of standing trees. Norway spruce.] Meddelelser fra Det norske Skogfors $\emptyset$ ksvesen 22:543574

Vidal C, Alberdi IA, Mateo LH, Redmond JJ (2016) National forest inventories: assessment of wood availability and use. Springer

Waser L, Ginzler C, Rehush N (2017) Wall-to-wall tree type mapping from countrywide airborne remote sensing surveys. Remote Sens $9: 1-24$

Publisher's note Springer Nature remains neutral with regard to jurisdictional claims in published maps and institutional affiliations.

\section{Affiliations}

\section{Johannes Rahlf $^{1}$ - Marius Hauglin ${ }^{1} \cdot$ Rasmus Astrup $^{1} \cdot$ Johannes Breidenbach $^{1}$}

Marius Hauglin

marius.hauglin@nibio.no

Rasmus Astrup

rasmus.astrup@nibio.no

1 Division of Forest and Forest Resources, NIBIO (Norwegian Institute for Bioeconomy Research), Høgskoleveien 8, 1433 Ås, Norway 